\title{
Mucosa-associated lymphoid tissue lymphoma on right lower eyelid previously diagnosed as lymphoid hyperplasia
}

Yang Seok Kim,

Young Cheon Na,

Woo Hoe Huh,

Ji Min Kim

Department of Plastic and

Reconstructive Surgery, Wonkwang

University Hospital, Iksan, Korea
Mucosa-associated lymphoid tissue (MALT) lymphoma is an uncommon form of non-Hodgkin lymphoma involving the mucosa-associated lymphoid tissue. Most commonly affected organ is the stomach. But, it could affect almost every organ in the whole body. If they have suspicious lesion, excision biopsy could be made. For staging, blood test including blood smear, abdomen and chest tomography or scan will be checked. Also, bone marrow test can be done if it is needed. The patient had visited the clinic for palpable mass on right lower eyelid. With excisional biopsy, it was diagnosed as lymphoid hyperplasia on pathologic test. But 2 years later, the patient came with recurrent symptom for our department with worry. At that time, we recommended excisional soft tissue biopsy under general anesthesia. Unfortunately, it was revealed MALT lymphoma on pathologic finding. It turned out to be stage 3 in Ann Arbor staging system without B symptoms. Hematologic consultation was made and she was treated with adjuvant chemotherapy for eight cycles to complete remission. We report a case of MALT lymphoma on subcutaneous tissue at right lower eyelid previously diagnosed as lymphoid hyperplasia.

Keywords: Lymphoid hyperplasia / Mucosa-associated lymphoid tissue / Non-Hodgkin lymphoma

\section{INTRODUCTION}

Mucosa-associated lymphoid tissue (MALT) lymphoma is an uncommon form of non-Hodgkin lymphoma (NHL) involving the mucosa-associated lymphoid tissue. In the World Health Organization classification, it is listed as a malignant lymphoma. Most commonly affected organ is the stomach. But, it could affect almost every organ in the whole body. If they have suspicious lesion, excision biopsy could be made. For staging, blood test including blood smear, abdomen and chest tomography or scan will be checked. Also, bone marrow test can be done if it is

\section{Correspondence: Young Cheon Na}

Department of Plastic and Reconstructive Surgery, Wonkwang University Hospital, 895 Muwang-ro, Iksan 54538, Korea

E-mail: ycnadr@hanmail.net

Received September 11, 2018 / Revised October 31, 2018 / Accepted November 2, 2018 needed. The patient visited the clinic for palpable mass on right lower eyelid. And it was revealed as lymphoid hyperplasia on pathologic findings. But 2 years later, the patient came with recurrent symptom for our department with worry. We recommended excisional soft tissue biopsy. Unfortunately, it was revealed as MALT lymphoma on pathologic finding. We report a case of MALT lymphoma on subcutaneous tissue at right lower eyelid previously diagnosed as lymphoid hyperplasia.

\section{CASE REPORT}

A 56-year-old female was presented with recurred palpable mass of $1 \times 1 \mathrm{~cm}$ size on her right lower eyelid. She had visited a clinic for palpable mass on right lower eyelid 2 years before. With excisional biopsy, it was diagnosed as lymphoid hyperpla- 

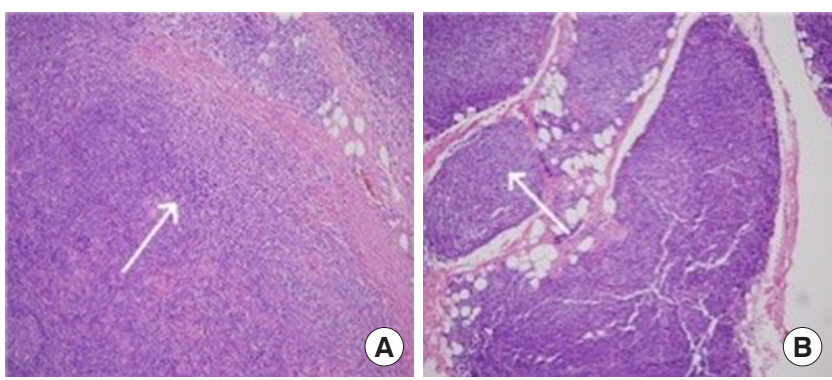

Fig. 1. (A) In the first biopsy of 2 years ago, it was revealed as lymphoid hyperplasia with proliferation of lymphocyte but there is no bizarre patterns (arrow; H\&E, $\times 100$ ). (B) In the final biopsy, bizarre nodular infiltration and differentiations of lymphocyte was observed with forming lymphoepithelial lesion (arrow; H\&E, $\times 100$ ). After all, it turned out to be mucosa-associated lymphoid tissue lymphoma.

sia on pathologic test (Fig. 1A). But with enhanced neck computed tomography (CT), the radiologist recommended a further evaluation because it couldn't rule out malignant lymphoma for ambiguous haziness around a mass. As she had refused an additional examination for ruling out malignant lymphoma, any further exam was not proceeded and follow-up check was loss for 2 years.

In this visit, she complained the recurrent palpable mass with growing and also wanted to excisional biopsy to know exactly what it is. The patient underwent excisional biopsy at the same site of right lower eyelid again with general anesthesia. In the operation, a yellowish oval-shaped mass was found adhered to orbicularis oculi muscle which was confused with fat mass from right lower eyelid was revealed as MALT lymphoma on pathologic finding (Fig. 1B). Immunohistological stain showed that $\mathrm{CD} 20, \mathrm{CD} 79 \mathrm{a}$ and reactive CD3-positive $\mathrm{T}$ cells were positive. But cyclin D1 was negative. Complete blood count showed normal leukocyte count and neutrophil count. Liver function tests, lactate dehydrogenase (LDH), beta-2-microglobulin, and serum protein electrophoresis were normal. Serologic tests for human immunodeficiency virus, hepatitis B virus, and hepatitis $\mathrm{C}$ virus (HCV) were negative. Serology studies for Chlamydia psittaci, Chlamydia trachomatis, and Chlamydia pneumoniae were negative. Immunoglobulin E (IgE) level was normal. There was no clinical or laboratory evidence of pre-existing autoimmune disease.

Consulting with hematologist, the positron emission tomography-computed tomography (PET-CT) and enhanced neck CT was performed after operation to tumor staging and showed stage III MALT lymphoma with invasion of both cervical and abdominal lymph node in Ann Arbor staging system (Fig. 2). Also the patient have no B symptoms. At a bone marrow biopsy, karyotype was normal, without bone marrow involvement.
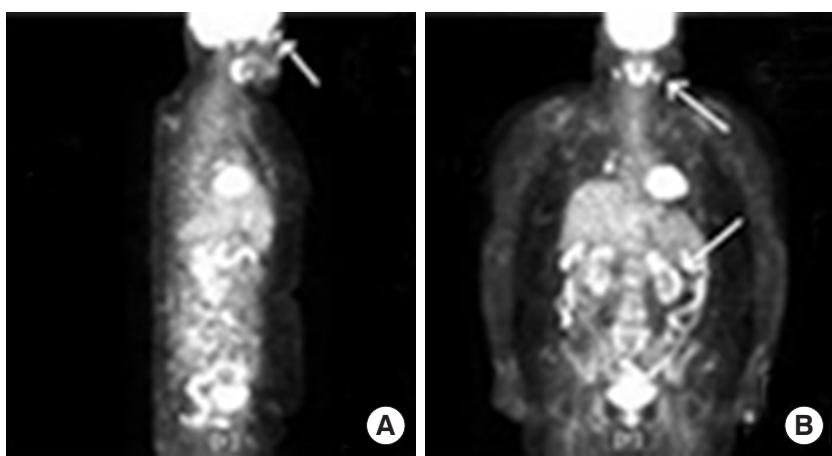

Fig. 2. Postoperative positron emission tomography-computed tomography showing focal hypermetabolism (SUV 4.5) at right lower eyelid (A, arrow) and multifocal hypermetabolism at both cervical (SUV 3.5) and abdominal (SUV 3.8) lymph nodes (B, arrows). SUV, standardized uptake value.

The patient received eight cycles of rituximab, cyclophosphamide, vincristine, and prednisone with complete remission for 2 years.

\section{DISCUSSION}

MALT lymphoma usually originates from B lymphocyte that occurs in reactive lymphoid tissue with secondary inflammation. Most commonly affected organ is the stomach. But, this type of disease may affect orbit, ocular adnexa, intestine, lung, salivary gland, thyroid, and skin [1]. In fact, 5\% of all NHL patients was affected on ocular adnexa. Interestingly, 15\%-20\% of these are aggressive (diffuse large B cell mantle cell lymphoma) and 80\%$85 \%$ of these are indolent (follicular or MALT type) [2].

The ocular adnexal extranodal marginal zone lymphoma is rare and usually presents with localized disease rather than systemic disease [3]. Bilateral involvement was reported in 10\%$15 \%$ of the cases [4]. Histologically, it is characterized by proliferation of colonization of reactive germinal centers, lymphoepithelial lesion, bizarre epithelial infiltration and differentiation of plasma cells. The MALT lymphoma concept suggests that this type of tumors are usually arise from chronic stimulated lymphoid tissue by prolonged infections and/or autoimmune diseases and correspond to cells of postfollicular differentiation stages $[5,6]$.

Chronic inflammation plays a huge role with exogenous and endogenous antigens. Usually this type of tumors have association of Helicobacter pylori with gastric diseases, Borrelia burgdorferi with cutaneous tumors, $C$. psittaci with ocular adnexal MALT lymphoma $[7,8]$. A case of extranodal marginal zone lymphoma of the ocular adnexae and subcutaneous involvement in association with chronic HCV infection was reported [9].

In fact, patients with this type of tumors have high prevalence 
of Sjogren syndrome, Hashimoto thyroiditis such as thyroid gland and salivary gland, respectively and also other autoimmune diseases. This can be the hypothesis that endogenous antigens could be the trigger to the tumor formation for that site by means of inflammatory reactions resulting abnormal activation of NF-kB pathway and uncontrolled B-cell expansion [10]. In these days, some studies revealed that Immunoglobulin G4 (IgG4) sclerosing disease is associated with lymphoproliferative disorders. Middle aged men is more affected by multiple benign mass. The pathogenesis is unknown, it is believed to be autoimmune. But, primary cutaneous marginal zone lymphomas have high IgG4 expression (39\%), noncutaneous MALT lymphomas, located in ocular adnexa, rarely expressed IgG4 [11].

Genetical aberration is associated with MALT lymphomas. It is also seen some structural chromosome abnormalities and numeric abnormalities. Almost trisomies and translocations. For examples, the $\mathrm{t}(1 ; 14)(\mathrm{p} 22 ; \mathrm{q} 32), \mathrm{t}(11 ; 18)(\mathrm{q} 21 ; \mathrm{q} 21), \mathrm{t}(14 ; 18)$ (q32;q21) and trisomies 3 and 18. It is largely related to MALT lymphoma.

Ocular adnexa, orbit, skin and salivary glands mainly express the $\mathrm{t}(14 ; 18)(\mathrm{q} 32 ; \mathrm{q} 21)$, but pulmonary and gastric tumors mainly express the $t(11 ; 18)(\mathrm{q} 21 ; \mathrm{q} 21)$. The $\mathrm{t}(14 ; 18)(\mathrm{q} 32 ; \mathrm{q} 21)$ is most frequently observed chromosomic translocation and it is strongly related to MALT lymphoma, also expressed in rare cases of extranodal diffuse large B-cell lymphoma. Chromosome 3 trisomy is usually involved with aged $>50$ years and the orbital involvement is diagnosed about $81 \%$ out of all cases. But chromosome 18 trisomy is usually involved with aged $<50$ years and the conjunctival involvement is frequently diagnosed $[12,13]$.

Management of MALT lymphoma depends on the organ involvement and the stage of disease. For NHL's staging, the 1971 modified Ann Abor staging system is usually considered.

Four disease stages are: an involvement of a single lymph node region (stage I) or a single extra-lymphatic site (stage I E), an involvement of two or more lymph node regions on the same side of the diaphragm (stage II), involvement of lymph nodes in both sides of the diaphragm \pm extra-lymphatic site \pm spleen or both (stage III, sage III E, stage III S, stage III ES), a disseminated disease (stage IV).

Also, two subgroups can be distinguished based on symptoms: (A) for asymptomatic patients, and (B) for patients with unexplained weight loss of more than $10 \%$ of body weight in the months previous to admission, unexplained fever with temperature above $38^{\circ} \mathrm{C}$ and night sweats [14]. But there is some limitation of disease staging for modified Ann Arbor staging system like prognostic difference of affected regional variations. Therefore, a new TNM-based staging system was oriented for primary orbital adnexa lymphomas under the auspices of the American Joint Committee on Cancer [15].

Treatment of MALT lymphoma requires a multidisciplinary approach including surgeon, radiotherapist and hematologist. In most patients, local treatment including radiation therapy or surgery may be adequate to deal with the disease. But, if the disease has spread or has been refractory on antibiotics, chemotherapy may need to be considered. Excisional biopsy of mass is essential procedure not a complete curative purpose but a diagnosis of MALT lymphoma because it could help for immunophenotyping analysis or histological confirm. When simple excision alone as complete curative treatment of MALT lymphoma is dangerous because it could tend to local relapse more frequently than radiotherapy alone. So, the role of surgery is limited a side of diagnostic tools not a total curative [16]. Radiotherapy for lymphoma is considered the standard treatment of local involvement of this disease without disseminations. Also, it is proven that radiotherapy could control the local relapse of the disease regardless of its types of lymphoma. In latest study, 77 patient treated with radiotherapy alone over a period of 20 years showed a 5 years and 10 years overall survival of $97.6 \%$ and $93.5 \%$ respectively [17]. But obviously, complications of radiotherapy for ocular area are shown up for ocular toxicity in forms of immediate and late complications. Immediate complications are presented by conjunctivitis or eyelid irritations. Late complications are included for retinal vasculopathy, optic neuropathy, cataract formations [18]. Chemotherapy for treatment of MALT lymphoma could be used that single agent (chlorambucil, fludarabine, and pentostatin) or CVP regimen (cyclophosphamide, vincristine, and prednisone) intended for low toxicity. It is utilized systemic involvement or not. Sasai et al. [19] suggested no meaningful difference in overall survival rate for patient with MALT lymphoma comparing effectiveness of radiotherapy with single agent chemotherapy and combination chemotherapy. It seems that adjunctive chemotherapy treatment with radiotherapy did not add any benefits than chemotherapy treatment alone. An overall 5-year survival rate of this disease is ranging between $54 \%$ and $94 \%$ depending on studies. There is some positive and negative prognostic factors. The positive prognostic factors are limited disease, good performance status and absence of systemic symptoms. Also, It is revealed that risk difference of primary site of presentation including conjunctival tumor shown lowest risk but eyelid tumor shown highest risk. The negative prognostic factors are advanced staged disease, 60-64 years aged, nodal involvement, elevated serum LDH level $[16,19,20]$. Because of ambiguous CT findings, we recommended further evaluation despite of a first biopsy finding revealed with lymphoid hyperplasia. A patient 
denied another studies at all. By doing so, it was delayed proper diagnosis and treatment of this malignancy. Therefore, the authors recommend further evaluation or closed follow-up to a patient with any doubtful pieces whether pathologic findings were benign like lymphoid hyperplasia or not as we reported.

\section{NOTES}

\section{Conflict of interest}

No potential conflict of interest relevant to this article was reported.

\section{Ethical approval}

The study was performed in accordance with the principles of the Declaration of Helsinki. Written informed consent was obtained.

\section{Patient consent}

The patient provided written informed consent for the publication and the use of her images.

\section{ORCID}

Yang Seok Kim https://orcid.org/0000-0003-3161-7284

Young Cheon Na https://orcid.org/0000-0003-3136-0351

Woo Hoe Huh https://orcid.org/0000-0002-1379-7122

Ji Min Kim https://orcid.org/0000-0002-9819-0775

\section{REFERENCES}

1. Zucca E, Conconi A, Pedrinis E, Cortelazzo S, Motta T, Gospodarowicz MK, et al. Nongastric marginal zone B-cell lymphoma of mucosa-associated lymphoid tissue. Blood 2003;101:248995.

2. Bairey O, Kremer I, Rakowsky E, Hadar H, Shaklai M. Orbital and adnexal involvement in systemic non-Hodgkin's lymphoma. Cancer 1994;73:2395-9.

3. Stefanovic A, Lossos IS. Extranodal marginal zone lymphoma of the ocular adnexa. Blood 2009;114:501-10.

4. Ferreri AJ, Dolcetti R, Du MQ, Doglioni C, Resti AG, Politi LS, et al. Ocular adnexal MALT lymphoma: an intriguing model for antigen-driven lymphomagenesis and microbial-targeted therapy. Ann Oncol 2008;19:835-46.

5. Qin Y, Greiner A, Trunk MJ, Schmausser B, Ott MM, MullerHermelink HK. Somatic hypermutation in low-grade mucosaassociated lymphoid tissue-type B-cell lymphoma. Blood 1995; 86:3528-34.

6. Greiner A, Marx A, Heesemann J, Leebmann J, Schmausser B, Muller-Hermelink HK. Idiotype identity in a MALT-type lym- phoma and B cells in Helicobacter pylori associated chronic gastritis. Lab Invest 1994;70:572-8.

7. Ferreri AJ, Guidoboni M, Ponzoni M, De Conciliis C, Dell'Oro $\mathrm{S}$, Fleischhauer K, et al. Evidence for an association between Chlamydia psittaci and ocular adnexal lymphomas. J Natl Cancer Inst 2004;96:586-94.

8. Lecuit M, Abachin E, Martin A, Poyart C, Pochart P, Suarez F, et al. Immunoproliferative small intestinal disease associated with Campylobacter jejuni. N Engl J Med 2004;350:239-48.

9. Vincenti D, Orofino N, Ferrario A, Goldaniga M, Rossi F, Olivero $\mathrm{B}$, et al. Unilateral exophthalmos and multiple subcutaneous nodules as a result of extranodal marginal zone lymphoma. J Clin Oncol 2012;30:e69-73.

10. Gruenberger B, Woehrer S, Troch M, Hauff W, Lukas J, Streubel B, et al. Assessment of the role of hepatitis C, Helicobacter pylori and autoimmunity in MALT lymphoma of the ocular adnexa in 45 Austrian patients. Acta Oncol 2008;47:355-9.

11. Brenner I, Roth S, Puppe B, Wobser M, Rosenwald A, Geissinger E. Primary cutaneous marginal zone lymphomas with plasmacytic differentiation show frequent IgG4 expression. Mod Pathol 2013;26:1568-76.

12. Chanudet E, Zhou Y, Bacon CM, Wotherspoon AC, MullerHermelink HK, Adam P, et al. Chlamydia psittaci is variably associated with ocular adnexal MALT lymphoma in different geographical regions. J Pathol 2006;209:344-51.

13. Tanimoto K, Kaneko A, Suzuki S, Sekiguchi N, Watanabe T, Kobayashi Y, et al. Primary ocular adnexal MALT lymphoma: a long-term follow-up study of 114 patients. Jpn J Clin Oncol 2007;37:337-44.

14. Carbone PP, Kaplan HS, Musshoff K, Smithers DW, Tubiana M. Report of the Committee on Hodgkin's Disease Staging Classification. Cancer Res 1971;31:1860-1.

15. Coupland SE, White VA, Rootman J, Damato B, Finger PT. TNM staging of ocular adnexal lymphomas. In: Edge SE, Byrd DR, Carducci MA, Compton CA, editors. AJCC Cancer Staging Manual. 7th ed. New York: Springer; 2009.

16. Coupland SE, Hellmich M, Auw-Haedrich C, Lee WR, Stein H. Prognostic value of cell-cycle markers in ocular adnexal lymphoma: an assessment of 230 cases. Graefes Arch Clin Exp Ophthalmol 2004;242:130-45.

17. Harada K, Murakami N, Kitaguchi M, Sekii S, Takahashi K, Yoshio K, et al. Localized ocular adnexal mucosa-associated lymphoid tissue lymphoma treated with radiation therapy: a long-term outcome in 86 patients with 104 treated eyes. Int J Radiat Oncol Biol Phys 2014;88:650-4.

18. Woolf DK, Kuhan H, Shoffren O, Akinnawo EM, Sivagurunathan B, Boyce $\mathrm{H}$, et al. Outcomes of primary lymphoma of the ocular adnexa (orbital lymphoma) treated with radiotherapy. 
Clin Oncol (R Coll Radiol) 2015;27:153-9.

19. Sasai K, Yamabe H, Dodo Y, Kashii S, Nagata Y, Hiraoka M. Non-Hodgkin's lymphoma of the ocular adnexa. Acta Oncol 2001;40:485-90.

20. Martinet S, Ozsahin M, Belkacemi Y, Landmann C, Poort- mans $\mathrm{P}$, Oehlere $\mathrm{C}$, et al. Outcome and prognostic factors in orbital lymphoma: a Rare Cancer Network study on 90 consecutive patients treated with radiotherapy. Int J Radiat Oncol Biol Phys 2003;55:892-8. 